\title{
25 Gauge Pars Plana Vitrectomy Results in Idiopathic Macular Holes
}

İdiyopatik Makula Deliği Tedavisinde 25 Gauge Pars Plana Vitrektomi Sonuçlarımız

\author{
Osman Bulut Ocak', Ziya Kapran². \\ 1-Sağlık Bilimleri Üniversitesi, Beyoğlu Göz Eğitim ve Araştırma Hastanesi, İSTANBUL, 2- Maltepe Üniversitesi, Göz Hastalıkları Ana \\ Bilim Dali, İSTANBUL
}

\begin{abstract}
Purpose: To evaluate the anatomical and functional efficacy, safety and complications of 25 gauge (G) sutureless pars plana vitrectomy (PPV) in idiopathic macular holes.

Material and Methods: Between March 2005 - May 2008, 30 eyes with 28 patients that had undergone 25 G PPV in our clinic were included in the study. Pre- and post-operative visual acuities, intraoperative and postoperative complications were noted, retrospectively.

Results: The mean age of the patients was $65 \pm 10.68$ (range 40 -84) years and 30 eyes of 18 females (64.2\%) and 10 males (35.8\%) were studied. 22 patients (73.3\%) had grade 3, 6 patients (20\%) had grade 4 and 2 patients (6.7\%) had grade 2 macular holes. The mean pre- operative best corrected visual acuity (BCVA) of the patients were $0.12 \pm 0.09$ (logMAR 0.98 \pm 0.33 , range $0.05-0.4$ ). Survey of macular holes was $9.55 \pm 8.97$ months $(1-24$ months). The mean follow-up was $13.81 \pm 9.44$ (range 1-30) months and 29 of 30 eyes (96.6\%) achieved anatomical success. BCVA was decreased statistically significant between preand post-operatively $(p<0.05)$. Postoperative retina pigment epithelium (RPE) changes were seen in 9 (30\%) eyes, cataract was seen in 8 (27.67\%) eyes, hypotony was seen in $3(10 \%)$ eyes and retinal detachment was seen in one (3.34\%) eyes.

Conclusion: The 25 G sutureless vitrectomy technique is anatomically and functionally effective in idiopathic macular holes.

ÖZET

Amaç: Ídiyopatik makula deliği cerrahi tedavisinde uygulanan 25 gauge $(G)$ pars plana vitrektomi (PPV) cerrahisinin anatomik ve fonksiyonel başarısını ve komplikasyonlarını değerlendirmek.

Gereç ve Yöntemler: Mart 2005 - Mayls 2008 tarihleri arasında hastanemizde makula deliği nedeniyle vitreoretinal cerrahi geçiren 28 hastanın 30 gözüne ait veriler retrospektif olarak incelendi ve olgular anatomik ve fonksiyonel başarı ile görülen komplikasyonlar açısından değerlendirildi.

Bulgular: Yasları 40 ile 84 arasında değişen (ortalama $65 \pm 10,68$ yll) olguların 18 'i $(\% 64,2)$ kadın ve 10 'u $(\% 35,8)$ erkekti. 22 olguda $(\% 73,3)$ evre 3, 6 olguda (\%20) evre 4, 2 olguda ise $(\% 6,7)$ evre 2 makuler delik mevcut idi. Cerrahi öncesi en iyi düzeltilmiş görme keskinlikleri (EDGK) ortalama 0,12 $\pm 0,09$ (logMAR $0,98 \pm 0,33,0,05-0,4$ arasi) olarak saptandl. Makula deliklerinin süresi ortalama 9,55 $\pm 8,97$ ay idi. (1 24 ay) 25 G PPV cerrahisi sonrast ortalama 13,81 \pm 9,44 ay (1-30 ay) takip edilen 30 gözün 29 'unda $(\% 96,6)$ anatomik başarı elde edildi. Olguların cerrahi öncesi ve sonrası EDGK arasındaki fark istatistiksel olarak anlamlıydı $(p<0,05)$. Ameliyat sonrası, 9 olguda (\%30) retina pigment epiteli (RPE) değişiklikleri, 8 olguda $(\% 26,67)$ katarakt, 3 olguda $(\% 10)$ hipotoni ve 1 olguda $(\% 3,34)$ retina dekolmanı gelişti.

Sonuç: İdiyopatik makula deliği cerrahi tedavisinde 25 G sütürsüz vitrektomi tekniği hem anatomik hem fonksiyonel iyileşme açısından etkili bulunmuştur.
\end{abstract}

Key Words:

25 G vitrectomy,

Macular hole,

Sutureless vitrectomy

Anahtar Kelimeler:

$25 \mathrm{G}$ vitrektomi,

Maküla deliği,

Sütürsüz vitrektomi

\section{GíRIŞ}

Makula deliği 55 yasın üzerindeki popülasyonda 33/10000 oranında görülen, görmeyi ciddi şekilde tehdit eden göz hastalıklarındandır (1-3). Çoğunluğu idiyopatik olan mauler deliklerin etyopatolojisi tam olarak anlaşılmamakla birlikte bu konuda çok sayıda teori öneri sürülmüştür. $(4,5)$ İlk olarak idiyopatik makula deliği olușumunda en önemli faktör olarak, arka vitre dekolmanı (AVD) sırasında gelişen anteroposterior vitreomakular traksiyon üzerinde durulmuştur. $(6,7)$ Worst, makuler deliklerin premakular bursa kaynaklı olduğunu ve bu yapının foveada anteroposterior traksiyon yaparak makuler deliğe neden olabileceğini bildirmiştir. (8) Gass ise prefoveal vitreus korteksinin fokal kontraksiyonuna bağlı oluşan tanjansiyel traksiyon ile foveal retinanın öne doğru gelmesi ile makula deliği gelişimi başladığını öne sürülmüştür. (9) Kadınlarda daha fazla görülen makula deliklerine, ayrıca travma ve bazı diğer oküler patolojiler de sebep olabilmektedir (1).

Günümüzde uygulanan en etkin tedavi yöntemi internal limitan membran (İLM) soyulmasıyla ile birlikte

Correspondence: Osman Bulut Ocak, Sağlık Bilimleri Üniversitesi, Beyoğlu Göz Eğitim ve Araştırma Hastanesi, Bereketzade Mah. Kuledibi Sok. No: 2, Şişhane, İstanbul Email: bulutocak@gmail.com Phone: +90 05334122179

Cite this article as: Ocak OB, Kapran Z. 25 Gauge Pars Plana Vitrectomy Results Iin Idiopathic Macular Holes. Phnx Med J. 2020;2(1):11-15. 


\section{Ocak et al.}

uygulanan pars plana vitrektomi (PPV) cerrahisidir $(10,11)$. Bu sayede makula üzerindeki vitreus serbestleştirilip, delik kenarındaki retina tabakasının yatıştırılması mümkün olmaktadır.

25 Gauge (25G) sütürsüz vitrektomi tekniği ilk olarak Fujii ve ark. tarafindan 2002 yılında uygulanmıştır (12). Bu teknik, konvansiyonel 20 Gauge vitrektomilerden farklı olarak konjonktival peritomi yapılmadan üç girişli sütürsüz vitrektomi yapılmasına olanak sağlamaktadır. Literatürde, $25 \mathrm{G}$ sütürsüz vitrektomi tekniği ile başarılı sonuçlar bildirilmektedir (13-15)

$\mathrm{Bu}$ çalışmamızda kliniğimizde makula deliği olgularına uyguladığımız cerrahi tedavinin anatomik ve fonksiyonel başarı oranları ve komplikasyonlar incelenmiştir.

\section{MATERYAL ve METOD}

$\mathrm{Bu}$ çalışmamızda Mart 2005-Mayıs 2008 tarihleri arasında hastanemizde makula deliği nedeniyle vitreoretinal cerrahi geçiren 28 hastanın 30 gözü retrospektif olarak değerlendirildi. Tüm olgulardan, operasyon için sözlü ve yazılı onam alınmış olup, çalışmamızın, Prof. Dr. N. Reşat Belger Eğitim ve Araştırma Hastanesi Etik Kurulu, 2015 yılı, 36 no'lu etik kurul kararı bulunmaktadır. Çalışmamız Helsinki insan hakları bildirgesine uygun olarak hazırlanmıştır.

Makula deliği dışında farklı etyolojilerle 25 G PPV yapılmış olgular, idiyopatik dışında farklı nedenlerle makula deliği gelişmiş olgular (travma vs.), takip süresi 1 aydan az olan olgular çalışma kapsamı dışında birakild1.

Olguların tümünün cerrahi ayrıntılı hikayeleri alındı. Tüm olguların en iyi düzeltilmiş görme keskinlikleri (EDGK), biomikroskopik ve oküler tansiyon muayenelerini içeren rutin oftalmolojik muayeneleri yapıldıktan sonra yine tüm olgulara ayrıntılı fundus muayeneleri yapild1.

Ameliyat öncesi; olguların şikayetleri, şikayetlerin başlama süresi ve olguların epidemiyolojik özellikleri kaydedildi. Oftalmik muayenede; EDGK, makula deliği evresi, göz içi basıncı (GİB) ve delik çapı değerleri kaydedildi. İntraoperatif, oluşan komplikasyonlar (infüzyon kanülünün yanlış yönlenmesi, retinal yırtık oluşumu, ani oküler tansiyon düşüşü, suprakoroidal hemoraji gelişimi vs.) eğer varsa kaydedildi. Post-operatif, EDGK, komplikasyonlar (hipotoni, Retina dekolmanı (RD)), takip süresi, EDGK, anatomik ve fonksiyonel başarı oranları değerlendirildi. Olguların görme keskinlikleri ETDRS eşeliyle alındı ve logMAR değerlerine çevrildi (logarithm of the minimum angle of resolution). Göz içi basınçları aplanasyon tonometrisi ile ölçüldü. Hipotoni olarak $6 \mathrm{mmHg}$ altı alındı. Makula deliklerinin evrelendirilmesi, fundus muayenesiyle ve optik koherens tomografi (OCT) sonuçlarıyla Gass sinıflamasına göre yapıldı. (16) $\mathrm{Bu}$ sinıflandırmada makuler delikler, anatomik olarak Evre 1 (fovea çevresinin seröz dekolmanı) Evre 4 (maküler delikle beraber pseudooperkulum ve arka vitre dekolmanı (AVD) varlığı) arasında sınıflandırılmıştır.

Ameliyat Tekniği: Lokal anestezi altında boyu $5 \mathrm{~mm}$ ve iç / diş çapları 0.37 / $0.56 \mathrm{~mm}$ olan $25 \mathrm{G}$ metal infüzyon kanülü yardımıyla transkonjonktival olarak alt temporalden infüzyon kanülü girişi yapılır. Üst temporal ve üst nazal kadranlardan ise endoilüminasyon ve vitreus kesicisi için, boyu $3.6 \mathrm{~mm}$ ve iç/dış çapları 0.57 / $0.62 \mathrm{~mm}$ olan poliyamid mikrokanüller yerleştirilir. Göze giriş yapılırken, konjonktiva bir pamuklu çubuk yardımıyla limbusa doğru sıvazlanır; bu şekilde konjonktival ve skleral kesinin aynı planda olmaması sağlanır. Daha sonra trokar üzerindeki mikrokanül ile birlikte skleradaki işaretlenen noktadan vitreus içine limbusa dik olarak yerleştirilir. Trokar geri çekilir ve $25 \mathrm{G}$ mikrokanül vitreus içinde kalır $(10,11)$.

Standart üçlü port sistemiyle pars plana vitrektomi yapılır. Ön ve mid vitreusun alınmasını takiben total arka vitreus dekolmanı oluşumu tamamlanır. Bir sonraki basamak İLM'nin soyulmasıdır. İLM boyandıktan sonra miringo vitreoretinal bıçakla temporal zondan horizontal olarak bir kenar kaldırılır ve dairesel hareketle flep olusturulur. Forsepsle tutulan flep dairesel olarak temporal damar arkları ve optik diske kadar soyulur. Amaç delik kenarlarının tamamen RPE'ne yapışmasıdır. Daha sonra hava-gaz değişimi yapılarak ameliyata son verilir.

Anatomik başarı; halka şeklindeki subretinal sıvının kaybolup delik kenarının düzleşmesi olarak kabul edildi. Anatomik başarı OCT ile doğrulandı. Fonksiyonel başarı kriteri, literatür esas alınarak, ETDRS eşeline göre 2 veya daha fazla sıra görme artış1 kabul edildi. $(10,11,13)$

Olguların istatistiki değerlendirmeleri SPSS ${ }^{\circledR} 16$ for Windows programı ile yapılmış olup, istatistiki test olarak eşleştirilmiş $\mathrm{t}$ testi kullanılmıştır. $\mathrm{P}<0,05$ istatistiksel olarak anlamlı kabul edilmiştir.

\section{BULGULAR}

Çalışmamıza idiyopatik makula deliği nedeniyle opere edilen 18'i kadın $(\% 64,2), 10$ 'u $(\% 35,8)$ erkek toplam 28 olgunun 30 gözü dahil edildi. 13 olgunun sağ gözü (\%46,43), 13 olgunun sol gözü $(\% 46,43), 2$ olgunun her iki gözü $(\% 7,14)$ opere edildi. Olguların yaşları 40 ile 84 arasında değişiyordu (ortalama: $65 \pm 10.8$ yaş). Hastaların görme azalması şikayetlerinin süresi 9,55 \pm 8,97 ay idi. ( $1-24$ ay) Makula deliklerinin çapları 187 ile $514 \mu$ (ortalama $390 \pm 120,12 \mu$, OCT ile) arasinda değişmekteydi. Makula deliği 2 gözde evre $2(\% 6,7)$, 22 gözde evre 3 (\%73,3), 6 gözde evre 4 (\%20) idi. Olguların 4'ü psödofak $(\% 13,3)$ ve 26 's1 ise $(\% 86,7)$ fakik idi. Olguların ameliyat öncesi en iyi düzeltilmiş görme keskinlikleri (EDGK) ortalama 0,12 \pm 0,09 $(\log$ MAR $0,98 \pm 0,33)$ idi (Tablo 1$)$. Minimum ve maksimum EDGK ise 0,05 (log MAR 1,2) - 0,4 $(\log M A R \quad 0,4)$ arasinda idi. 


\section{Phnx Med J. March, Volume 2 No 1}

Postoperatif son takip muayenesinde olguların EDGKleri 0,03 ile 0.6 arasındaydı (ortalama $0,19 \pm 0,12)(\log M A R \quad 1,3$ ile 0,3 arasi). Pre- ve postoperatif EDGK arasındaki fark ise istatistiksel olarak anlamlıyd $\quad(\mathrm{p}<0.05)$ (Tablo 1). Sonuç olarak 28 olgunun 30 gözü değerlendirildiğinde, 22 (\%73) gözde ameliyat öncesine göre görme keskinliğinde bir veya daha fazla sıra artışı bulundu. 7 (\%24) gözde postoperatif görme keskinliği ameliyat öncesiyle aynıydı. 1 (\%3) gözde ise görme keskinliğinde düşme tespit edildi (Tablo 2). Son muayenelerinde görme keskinliklerinde düşme tespit edilen vaka postoperatif 2. ayda RD gelişen hasta idi. Nüks eden ve persistan kalan makuler delik vakalarında görme aynı kaldı.

Fonksiyonel başarıya bakıldığında ise (en az iki sıra) görme artışı sağlanan hasta oranı ise \%56,6 olarak bulundu. 17 gözde fonksiyonel başarı sağlandı.

Preoperatif göz içi basınçları 14,36 $\pm 2,68 \mathrm{mmHg}$ (8-19 $\mathrm{mmHg}$ ) idi (Tablo 1). Son muayenede GİB 14,54 \pm 2,93 $\mathrm{mmHg}$ (7-18 $\mathrm{mmHg}$ arasi) bulundu. Pre- ve postoperatif son takip GİB açısından istatistiksel olarak anlamlı fark bulunmadı ( $\mathrm{p}>0.05)$ (Tablo 1).

Hiçbir olguda, intraoperatif komplikasyon gelişmedi. Ameliyat sırasında 20 gauge vitrektomiye geçiş gerekmedi. Hiçbir olguda sklerotomi sütürü konulmadı ve sklerotomilerden kaçak izlenmedi.

Ameliyat sonrası 1. günde yapılan muayenelerde 3 gözde ciddi hipotoni gelisti (sırasıyla 3, 4 ve $6 \mathrm{mmHg}$ ) (Tablo 3). Bu gözlerden ikisinde ek bir müdahale yapılmaksızın postoperatif 5. günde normal GİB değerlerine ulaşıldı. Hipotoni ile devam eden 1 göze ise postoperatif 7. günde intravitreal C3F8 enjeksiyonu yapıldı. Sonrasında hipotoninin düzeldiği gözlendi. 1 gözde $(\% 3,33)$ GİB 20 mmHg'dan yüksek bulundu. Olguların hepsinde ek cerrahi müdahaleye gerek kalmaksızın GİB kontrol altına alındı. Tüm olgularda son postoperatif kontrolde GIBB normal sinırlar içerisindeydi.

Postoperatif takiplerde \%30 oranında (9 göz) RPE değişiklikleri tespit edildi. Önceden nükleer opasitesi olan 8 gözde $(\% 26,6)$ ameliyat sonrası ortalama 9.ayda (4-20 ay) katarakt gelişimi görüldü ve olguların takipleri devam etti (Tablo 3). $\mathrm{Bu} 9$ olguya fakoemülsifikasyon cerrahisi ve katlanabilir GIL implantasyonu yapıldı. 6 olguda postoperatif son takip görme keskinliği artarken 2'sinde değişmedi.

1 olguda $(\% 3,34)$ ameliyat sonrası 2 . ayda retina dekolmanı gelişti (Tablo 3). Bu olguya yeniden PPV cerrahisi uygulandı. Olgunun son takip kontrolünde (9. Ayda) retina yatışık ve makuler delik kapalı olarak gözlendi. Makula deliğine bağlı reoperasyon yapılan olgu, persistan (ilk cerrahinin başarısız olduğu) makuler delik olgusu idi. Persistan delik vakasına 8. günde intravitreal $\mathrm{C} 3 \mathrm{~F} 8$ enjeksiyonu, ardindan 26. günde $25 \mathrm{G}$ revitrektomi ve C3F8 enjeksiyonu yapıld1. Reoperasyon sonrası makuler delik kapandı. Nüks (makuler deliği 6 ay kapalı kalan) makuler delik olgusu ise tekrar ameliyat olmayı kabul etmedi. Son yapılan

Tablo 1: Olguların pre- ve post-operatif EDGK ve GiB ortalamaları

\begin{tabular}{|l|l|l|l|l|l|l|}
\hline & $\begin{array}{l}\text { Pre-op } \\
\text { EDGK } \\
\text { (Snellen) }\end{array}$ & $\begin{array}{l}\text { Post-op } \\
\text { EDGK } \\
\text { (Snellen) }\end{array}$ & $\mathbf{p}^{*}$ & $\begin{array}{l}\text { Pre-op } \\
\text { GíB } \\
\text { (mmHg) }\end{array}$ & $\begin{array}{l}\text { Post-op } \\
\text { GíB } \\
(\mathbf{m m H g})\end{array}$ & $\mathbf{p}^{* *}$ \\
\hline Ort \pm SD & $0,12 \pm 0,09$ & $0,19 \pm 0,12$ & $<0,05$ & $14,36 \pm 2,68$ & $14,54 \pm 2,93$ & $>0,05$ \\
\hline
\end{tabular}

EDGK: En iyi düzeltilmiş görme keskinlikleri, GIB: göz içi basıncl, pre-op: preoperatif, post-op: postoperatif son takip, ort: ortalama, SD: standart sapma, Snellen: Snellen eşeli ile alınmış EDGK, *: Pre- , post- operatif EDGK arasındaki istatistiki değerlendirme (eşleştirilmiş $t$ testi), **: Pre-, post- operatif GIB arasındaki istatistiki değerlendirme (eşleştirilmiş $t$ testi),

Tablo 2: Olguların fonksiyonel sonuçları

\begin{tabular}{|c|c|c|}
\hline Görme keskinliği & Olgu sayısı (n) & \% \\
\hline EDGK artışı olan & 22 & 73,3 \\
\hline EDGK değişmeyen & 7 & 23,3 \\
\hline EDGK azalan & 1 & 3,34 \\
\hline
\end{tabular}

EDGK: En iyi düzeltilmiş görme keskinliği

Tablo 3: Komplikasyonlar

\begin{tabular}{|c|c|c|}
\hline Komplikasyon & Olgu sayısı (n) & \% \\
\hline Hipotoni & 3 & 10 \\
\hline Katarakt gelisimi & 8 & 26,67 \\
\hline Retina dekolmanı & 1 & 30,34 \\
\hline RPE değisikliği & 9 & 3,34 \\
\hline Persistan Delik & 1 & 30 \\
\hline
\end{tabular}




\section{Ocak et al.}

kontrol muayeneleri esnasinda toplam $29(\% 96,6)$ vakada makula deliği anatomik olarak kapalı bulundu. Tüm vakalarda bu sonuçlar OCT ile doğrulandı.

\section{TARTIŞMA}

İdiyopatik makula deliği 55 yaş üstünde $33 / 10000$ prevalansla görülmektedir $(17,18)$. Ortalama görülme yas1 65 olmakla beraber kadınlarda, erkeklere göre daha sık ortaya çıkmaktadır (11). Yaklaşık \%10 vakada başlama zamanı farklı da olsa bilateral görülmektedir (17-19). Bizim olgularımızın yaşı 40 ile 84 arasındaydı ve 28 tanesi $(\% 93,3) 55$ yaşın üzerindeydi. Kadın / erkek oranı ise 9 / 5 idi. 2 olguda $(\% 6,6)$ aynı zamanda diğer gözde de maküla deliği bulunmaktaydı.

Makula deliği cerrahisinde iyi cerrahi sonuçlar ile ilgi faktörler; kısa süreli olması, erken evre delik, ameliyat öncesi yüksek görme keskinliği olarak bildirilmektedir (20,21). Bizim olgularımızdaki deliklerin 22 tanesi $(\% 73,3)$ evre 3, 6 tanesi evre 4 (\%20) 2 tanesi ise $(\% 6,7)$ evre 2 idi. Şikayetlerin süresi 19 hasta $(\% 67,8)$ tarafindan biliniyordu ve 1-24 ay arasında değişiyordu (ort. 9,55 ay). Pre- ve post-operatif EDGK arasındaki fark istatistiksel olarak anlamlı idi $(p=0.01, p<0.05)$. Literatürde, makula deliğine uygulanan PPV'nin yüksek anatomik başarıyla birliktelik gösterdiği belirtilmiștir $(22,23)$. Bizim anatomik başarı oranımız da $(\% 96,6)$ literatürle uyumluluk göstermektedir.

2 veya daha fazla sıra fonksiyonel görme keskinliği artışı elde ettikleri olgu oranı, literatürde $\% 45$ ile $\% 85$ arasında değişmektedir (24-26) Çalışmamızda görme artıs1 olan olguların oranı \%73,3 (22 olgu) olarak bulduk. Fonksiyonel başarı kriterine uyan olgu oranı $\% 56,6$ (17 olgu) oldu. Son muayenede 7 gözde $(\% 23,33)$ EDGK değişmezken bir gözde $(\% 3,34)$ EDGK azalmış olarak bulundu.

Çeşitli çalışmalarda nüks delik oranı $\% 4,8$ ile $\% 23$ arasında değişmektedir $(27,28)$ Nüks cerrahiden 2-22 ay (ort. 12,5 ay) sonra olmaktadır. Bizim nüks oranımız \%3,4 oldu ve olgu reoperasyon istemedi. Mester ve ark. makula deliği cerrahisi geçirenlerde retina dekolmanı gelişme oranını \%7 olarak vermişlerdir (28).
Banker ve ark. yaptıkları çalışmada bu oranı \%11 olarak bildirmişlerdir (29). Makula deliği cerrahisi geçiren 98 olguluk bir seride retinal yırtık veya retina dekolmanı oranı \%17 bulunmuştur (30). Çalışmamızda postoperatif retina dekolmanı gelişen olgu sayısı bir (\%3.34) bulundu. $\mathrm{Bu}$ olguda retina dekolmanı postoperatif 2. ayda gelişti. Olgu, PPV ile başarıyla tedavi edildi. Ve son kontrolünde retina yatışık ve delik kapalı olarak gözlendi.

Daha önceki çalışmalarda postoperatif erken dönem GİB değerleri bildirilmiş olup, çoğunlukla postoperatif uzun dönemde (1. ay sonrası) GİB değişikliği gözlenmemiştir (12,13). Ancak Iberra ve ark.ve Yanyalı ve ark., GİB'de postoperatif ilk günde anlamlı düşüş bildirmişlerdir $(10,11)$. Bizim çalışmamızda ise, postoperatif 1 . günde 3 gözde ciddi hipotoni tespit edildi. 2 olguda postoperatif 5 . günde cerrahi müdahaleye gerek kalmaksızın GİB değerlerinde normal seviyelere yükseldi. 1 hastada ise düzelmeyen GİB nedeniyle 8. günde intravitreal $\mathrm{C} 3 \mathrm{~F} 8$ enjeksiyonu uygulanmıştır. GİB değerleri normal seviyeye gelen bu hastamızda koroid dekolmanı, katlantıları, vitreus hemorajisi veya endoftalmi gibi komplikasyonlar görülmemiştir fakat bu vakada persistan makuler delik saptanmıştır. Daha sonra olguya 8. Günde intravitreal C3F8 enjeksiyonu ve 20.günde 25G revitrektomi yapıld 1 ve makuler delik sonraki takiplerde kapalı olarak izlendi.

Literatürde postoperatif katarakt insidansı için \%18 80 arası değişken oranlar bildirilmiştir (31-33). Bizim çalışmamızda ise \%26,6 katarakt gelişimi gözlemledik. Katarakt gelişimi ortalama 9. ayda oldu. $\mathrm{Bu} 9$ olguya fakoemülsifikasyon cerrahisi ve katlanabilir GİL implantasyonu yapıldı. 6 gözde EDGK artarken 2 gözde ise değişmedi.

Çalışmamızın kısıtlılıkları; retrospektif olması, göreceli olarak az sayıda olgunun çalışmaya dahil edilmesi ve diğer vitrektomi çeşitleriyle karşılaştırma yapılmamış olmasıdır.

Sonuç olarak; 25 G sütürsüz PPV cerrahisi ile, makula deliği tedavisinde yüksek anatomik ve fonksiyonel başarı mümkün olabilmektedir.

\section{ÇIKAR İLIȘKIISI}

Tüm yazarlar çıkar çatışması ve finansal ilinti olmadığını beyan eder.

\section{KAYNAKLAR}

1. David B. Nelson, R. Lee Grantham, Dennis M. Marcus: Traumatic Giant Macular Hole. Retina 2001; 21:677-678.

2. Morgan CM, Schatz H: Idiopathic macular holes. Am J Ophthalmol 1985; 99:437-444

3. Gass JDM: Idiopathic senile macular hole: Its early stages and pathogenesis. Arch Ophthalmol 1988; 106:629-639.

4. Ryan SJ. Retina 5th ed. New York: Saunders 2013. Gaudric A, Tadayoni R. Macula Hole. Chapter 117, p.1969-75.

5. Kanski JJ, Bowling B, editor. Oftamologia clínica. 7th ed. Rio de Janeiro: Elsevier; 2012. p. 629

6. Schepens CL. Fundus changes caused by alterations of the vitreous body. Am J Ophthalmol. 1955; $39: 631$.

7. Reese AB, Jones IS, Cooper WC. Macular changes secondary to vitreous traction. Trans Am Ophthalmol Soc. 1966; 64:123.

8. Worst JGF. Cisternal systems of the fully developed vitreous body in the young adult. Trans Ophthalmol Soc UK. 1977; 97:550-554.

9. Gass JDM. Idiopathic senile macular hole: Its early stages and pathogenesis. Arch Ophthalmol. 1988; 106:629-639.

10. Ibarra MS, Hermel M, Prenner JL, Hassan TS. Longer-term outcomes of transconjunctival sutureless 25 Gauge vitrectomy. Am J Ophthalmol. 2005; 139:831-836.

11. Yanyali A, Celik E, Horozoglu F, Oner S, Nohutcu AF. 25Gauge transconjunctival sutureless pars plana vitrectomy. Eur J Ophthalmol. 2006; 16:141-147. 


\section{Phnx Med J. March, Volume 2 No 1}

12. Fujii GY, De Juan E Jr, Humayun MS, et al. Initial experience using the Transconjunctival sutureless vitrectomy system for vitreoretinal surgery. Ophthalmology. 2002;109:1814-20.

13. Rizzo S, Genovesi-Ebert F, Murri S, et al. 25Gauge, sutureless vitrectomy and standard 20-gauge pars plana vitrectomy in idiopathic epiretinal membrane surgery: a comparative pilot study. Graefes Arch Clin Exp Ophthalmol. 2006; 19:18 - 20.

14. Chang CJ, Chang YH, Chiang SY, Lin LT. Comparison of clear corneal phacoemulsification combined with 25Gauge transconjunctival sutureless vitrectomy and standard 20-gauge vitrectomy for patients with cataract and vitreoretinal diseases. J Cataract Refract Surg. 2005; 31:1198-207.

15. Shimada H, Nakashizuka H, Mori R, Mizutani Y. Expanded indications for 25Gauge transconjunctival vitrectomy. Jpn J Ophthalmol. 2005; 49:397-401.

16. Gass JD: Reappraisal of biomicroscopic classification of stages of development of a macular hole. Am J Ophthalmol.1995;119:752-759

17. Ho AC, Guyer DR, Fine SL. Macular Hole. Surv Ophthalmol 1998; 42:393-416

18. The Eye Disease Case-Control Study Group. Risk factors for idiopathic macular holes. Am J Ophthalmol. 1994; 118:754-761.

19. McCannel CA, Ensminger JL, Diehl NN, Hodge DN. Population-based incidence of macular holes. Ophthalmology. 2009;116:1366-139.

20. Wendel RT, Patel AC, Kelly NE, et al. Vitreous surgery for macular holes. Ophthalmology 1993; 100:1671-1676.

21. Kim JW, Freeman WR, Azen SP, et al. Prospective randomized trial of vitrectomy or observation for stage 2 macular holes. Am J Ophthalmol 1996; 121:605-614.

22. Leonard RE, Smiddy WE, Flynn HW Jr, Feuer W. Long-term visual outcomes in patients with successful macular hole surgery. Ophthalmology 1997; 104:1648-1652.

23. Hirata A, Yonemura N, HasumuraT, et al. Effect of infusion air pressure on visual field defects after macular hole surgery. Am J Ophthalmol 2000; 130:611-616.

24. Park DW, Sipperley JO, Sneed SR, et al. Macular hole surgery with ILM peeling and intravitreous air. Ophthalmology 1999; 106:1392-1398.

25. Haritoglou C, Gandorfer A, Gass CA, Schaumberger M, Ulbig MW, Kampik A. ICG- assisted peeling of the internal limitan membrane in macular hole surgery affects visual outcome: A clinicopathologic correlation. Am J Ophthalmol 2002; 134:836-841.

26. Johnson RN, Gass JDM. Idiopathic macular holes. Ophthalmology 1988; 95:917- 924.

27. Sulkes DJ, Smiddy WE, Flynn HW, et al. Outcomes of macular hole surgery in severely myopic eyes: A case control study. Am J Ophthalmol 2000; 130:335-339.

28. Mester V, Kuhn F. Internal limitan membrane removal in the management of fullthickness macular holes. Am J Ophthalmol 2000;129:769777.

29. Banker AS, Freeman WR, Kim JW, et al. Vision threatening complications of surgery for full-thickness macular holes. Vitrectomy for Macular Hole Study Group. Ophthalmology 1997; 104:1442-1452.

30. Park SS, Marcus DM, Duker JS, et al. Posterior segment complications after vitrectomy for macular hole. Ophthalmology 1995; 102:775-781.

31. Freeman W, Azen S, Kim J, et al. Vitrectomy for the treatment of full-thickness stage 3 or 4 macular holes. Arch Ophthalmol 1997; $115: 11-21$.

32. Haritoglou C, Gass CA, Schaumberger M, et al. Long-term follow-up after macular hole surgery with ILM peeling. Am J Ophthalmol 2002; 134:661-666.

33. Singh S, Byanju R, Pradhan S, Lamichhane G. Retrospective Study on Outcome of Macular Hole Surgery. Nepal J Ophthalmol. 2016; 8:139143. 